\title{
Pengelolaan Program Keahlian Ganda Guru KompetensiTeknik Kendaraan Ringan (TKR) dan Teknik Komputer Jaringan (TKJ) di SMKN 12 Malang
}

\author{
Tahta Maulana Ari Praja ${ }^{1}$, Yoto $^{2}$, dan Widiyanti ${ }^{3}$ \\ 1,2,3Program Studi S1 Pendidikan Teknik Mesin Jurusan Teknik Mesin \\ ${ }^{1,2,3}$ Fakultas Teknik Universitas Negeri Malang \\ $1,2,3$ Jalan Semarang No. 5, Malang 65145 \\ Email: tahtamaulana1997@gmail.com
}

\begin{abstract}
Abstrak: Keahlian ganda merupakan program yang dijalankan oleh Kementrian Pendidikan dan Kebudayaan dengan melibatkan berbagai pihak, yaitu Direktorat Jenderal GTK, PPPPTK, Dinas pendidikan kabupaten/kota, SMK, guru pembimbing, guru peserta Program Keahlian Ganda, program ini untuk terobosan kurangnya guru produktif di SMK. Tujuan Penelitian, untuk mengetahui persiapan, komponen pengelolaan, dan penilaian kegiatan keahlian ganda. Metode menggunakan pendekatan kualitatif dan menggunakan trianggulasi metode. Hasil penelitian diketahui peserta guru keahlian ganda umur harus dibawah 55 tahun, bukan guru honorer. Guru pendamping harus kompeten dengan keahlian tertentu dan mempunyai pengalaman mengajar minimal 5 tahun. Struktur progam yang digunakan dalam keahlian ganda semua sudah disusun oleh P4TK. Pelatihan menggunakan modul yang dijadikan acuan mengajar. Proses RPP dan belajar mengajar (ON) oleh peserta keahlia ganda menyesuaikan silabus sekolah. Dalam pembuatan RPP harus disesuaikan dengan KI/KD pada silabus. Penilainya meliputi ON-1, IN-1, ON-2, IN-2. Kriteria Capaian Minimal (KCM) memenuhi peserta keahlian ganda bisa melanjutkan ke tahap IN-1, dan seterusnya sampai IN-2. Untuk jadi peserta harus sesui syarat/kriteria yang telah ditentukan oleh Dirjen GTK, dan harus memilih guru yang berkometen di bidangnya untuk guru instruktur dan pendamping.
\end{abstract}

Kata Kunci: Persiapan pengelolaan, pengelolaan, Penilaian Guru Keahlian ganda

Pendidikan merupakan eskalator yang dapat meningkatkan kesejahteraan, derajat, martabat, dan harga diri manusia. Menurut teori human capital, pendidikan berpengaruh terhadap pertumbuhan ekonomi melalui peningkatan keterampilan dan produktivitas tenaga kerja (Benhabib \& Spiegel, 1994). Tirtarahardja dan Sulo (2005) berpendapat bahwa tujuan pendidikan memuat gambaran tentang nilai-nilai yang baik, luhur, pantas, benar, dan indah untuk kehidupan. Tujuan pendidikan memiliki dua fungsi yaitu memberikan arah kepada segenap kegiatan pendidikan dan merupakan sesuatu yang ingin dicapai oleh segenap kegiatan. Demi merealisasikan tujuan pendidikan tersebut, tentunya harus ditunjang dengan meningkatkan mutu pendidikan dengan cara memperbaiki proses pembelajaran melalui jalur pendidikan. Sekolah Menengah Kejuruan (SMK) merupakan sekolah pada jenjang pendidikan menengah yang memiliki fokus untuk mempersiapkan lulusannya sebagai tenaga yang terampil dan siap untuk memasuki dunia industri.

Kebutuhan dunia industri dan dunia usaha akan lulusan SMK yang terampil terus meningkat. Peningkatan jumlah SMK menyebabkan perubahan kebutuhan tenaga pendidik. Direktorat Jenderal Guru dan Tenaga Kependidikan (2016) menyatakan bahwa beberapa program keahlian di SMK mengalami kekurangan guru produktif sementara pada program keahlian mata pelajaran lainnya jumlah guru melebihi jumlah yang dibutuhkan, maka dari itu di SMKN 12 Malang di adakan program keahlian ganda. Guru di SMKN 12 Malang mendapat keahlian ganda atau Kompetensi Keahlian (Kompli) Teknik Kendaraan Ringan (TKR) dan Teknik Komputer Jaringan (TKJ)

Keahlian Ganda merupakan terobosan yang diharapkan dapat mengatasi masalah kekurangan guru produktif pada SMK. Salah satu cara strategis yang perlu dilakukan Pemerintah dalam jangka pendek adalah program sertifikasi keahlian dan sertifikasi pendidik bagi guru SMK yang selanjutnya disebut Program Keahlian Ganda.

Keahlian Ganda memungkinkan guru adaptif dapat mengajar matapelajaran produktif sehingga dapat mengatasi ketimpangan jumlah guru adaptif dan produktif. Selain itu progam keahlian ganda merupakan terobosan para guru pengajar yang sudah mendapatkan sertifikat keahlian tetapi belum mendapatkan sertifikasi pendidikan karena hal tersebut dapat dijadikan tunjangan profesi.

Berdasarkan uraian diatas maka fokus penelitian ini adalah mendeskripsikan dan menginter pretasikan hal-hal sebagai berikut: (1) persiapan keahlian ganda di SMKN 12 Malang, (2) pengelolaan kegiatan keahlian ganda di SMKN 12 Malang, dan (3) penilaian pengelolaan keahlian ganda di SMKN 12 Malang. 


\section{METODE}

Penelitian ini menggunakan pendekatan kualitatif untuk pelaksanaan penelitiannya. Arikunto (2013) menyebutkan ciri-ciri pendekatan kualitatif adalah (1) mempunyai sifat induktif, (2) melihat setting secara keseluruhan atau holistik, (3) memahami responden dari titik responden sendiri, (4) menekankan validitas penelitian, (5) menekankan pada setting alami, (6) mengutamakan proses dari pada hasil, (7) menggunakan non probilitas sampling (8) peneliti sebagai instrument kunci, (9) menganjurkan penggunaan triangulasi (10) menggantungkan diri pada teknik dasar studi lapangan, dan (11) melakukan analisis data sejak awal.

Rancangan penelitian yang akan digunakan adalah studi kasus. Yin dalam Putra (2013:181) mengemukakan bahwa studi kasus adalah suatu inkuiri empiris yang menyelidiki fenomena di dalam kehidupan nyata, bilamana batas-batas antara fenomena dan konteks tak tampak dengan tegas, dan dimana multisumber bukti dimanfaatkan. Lokasi penelitian berada pada SMKN 12 Malang Jl. Pahlawan, Balearjosari, Blimbing, Kota Malang, Jawa Timur 65126.

Menurut Rudin (2017:65) dalam melakukan penelitian, harus menguasai teknik pengumpulan data sehingga menghasilkan data yang relevan dengan penelitian. Teknik pengumpulan data yang digunakan adalah wawancara, observasi, dan dokumentasi. Sumber data diambil dari narasumber yang sesuai dengan kasus yang ada. Narasumber dalam penelitian ini meliputi Waka kurikulum, guru instruktur SMKN 12 Malang, guru pendamping SMKN 12, dan peserta keahlian ganda SMKN 12 Malang. Analisis data yang digunakan yaitu: (1) reduksi data, (2) display data, dan (3) kesimpulan. Untuk meminimalisir penyimpangan terhadap hasil temuan di lapangan saat penelitian menggunakan keabsahan data metode triangulasi dan member check. Sejalan dengan Moleong (2005) demi menetapkan keabsahan data (trustworthiness) data diperlukan teknik pemeriksaan

\section{HASIL PENELITIAN}

Pelaksanaan keahlian ganda bagi guru SMKN 12 Malang memiliki beberapa proses yaitu persiapan pengelolaan keahlian ganda di SMKN 12 Malang, pengelolaan kegiatan keahlian ganda di SMKN 12 Malang, Penilaian Pengelolaan Keahlian Ganda di SMKN 12 Malang.

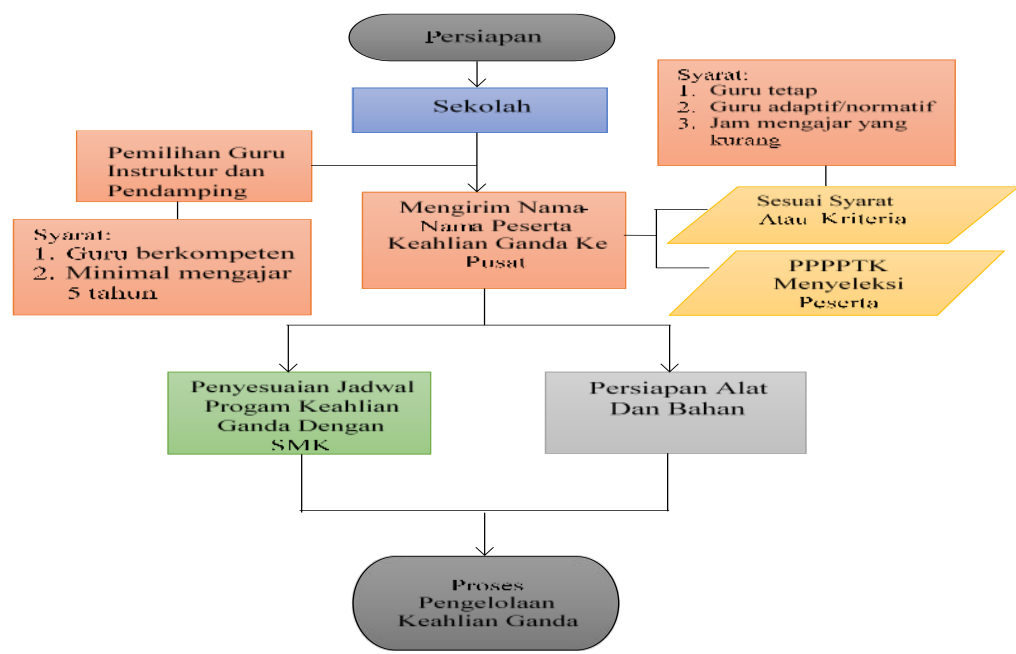

Gambar 1. Alur Persiapan Keahlian Ganda di SMKN 12 Malang

\section{Persiapan pengelolaan keahlian ganda di SMKN 12 Malang.}

Sebagai calon peserta langkah awal yang harus dilakukan yaitu memperhatikan syarat atau kriteria yang telah ditetapkan pusat. Syarat atau kriteria yang ditetapkan antara lain yaitu umur harus dibawah 55 tahun, guru tetap (bukan guru honorer), guru yang mempunyai kekurangan jam mengajar dan yang pasti berbadan sehat, guru adaptif/normatif.

Syarat dan kriteria yang ditentukan oleh pusat tidak begitu rumit, semua guru yang sekiranya memenuhi kriteria bisa mendaftar progam keahlian ganda tersebut melalui sekolah. Pihak SMKN 12 Malang tidak menghambat guru-guru yang akan mendaftar progam keahlian ganda. Nama-nama guru yang mencalonkan menjadi peserta keahlian ganda akan dikirim oleh SMKN 12 Malang dan akan diseleksi oleh pusat. Nama-nama guru yang lolos seleksi harus ikut pembekalan selama 4 hari lalu mengikuti beberapa tahap yang telah disusun oleh pusat.

Waktu pelatihan peserta keahlian ganda didampingi oleh guru pendamping dan guru instruktur Pemilihan guru pendamping juga tidak sembarangan. Kepala sekolah menunjuk guru yang sekiranya berkompeten dibidang keahlian tertentu 
untuk dijadikan pendamping, dipastikan guru pendamping keahlian ganda harus mempunyai sertifikat pendidik dan mempunyai pengalaman mengajar selama 5 tahun.

Pemilihan Instruktur pun sama namun bedanya menjadi guru instruktur ada pelatihannya. Ketika peserta keahlian ganda mengikuti pelatihan, jadwal yang digunakan sudah disesuaikan oleh pihak sekolah. Tidak hanya jadwalnya saja, peralatannya pun juga harus disiapkan. Apabila peralatan untuk praktek memadai juga akan mempengaruhi lancarnya prestasi belajar pada saat pelatihan.

\section{Pengelolaan kegiatan keahlian ganda di SMKN 12 Malang}

Progam keahlian ganda merupakan solusi yang tepat untuk dijadikan solusi jangka pendek untuk mengatasi kekurangan guru produktif di SMK.

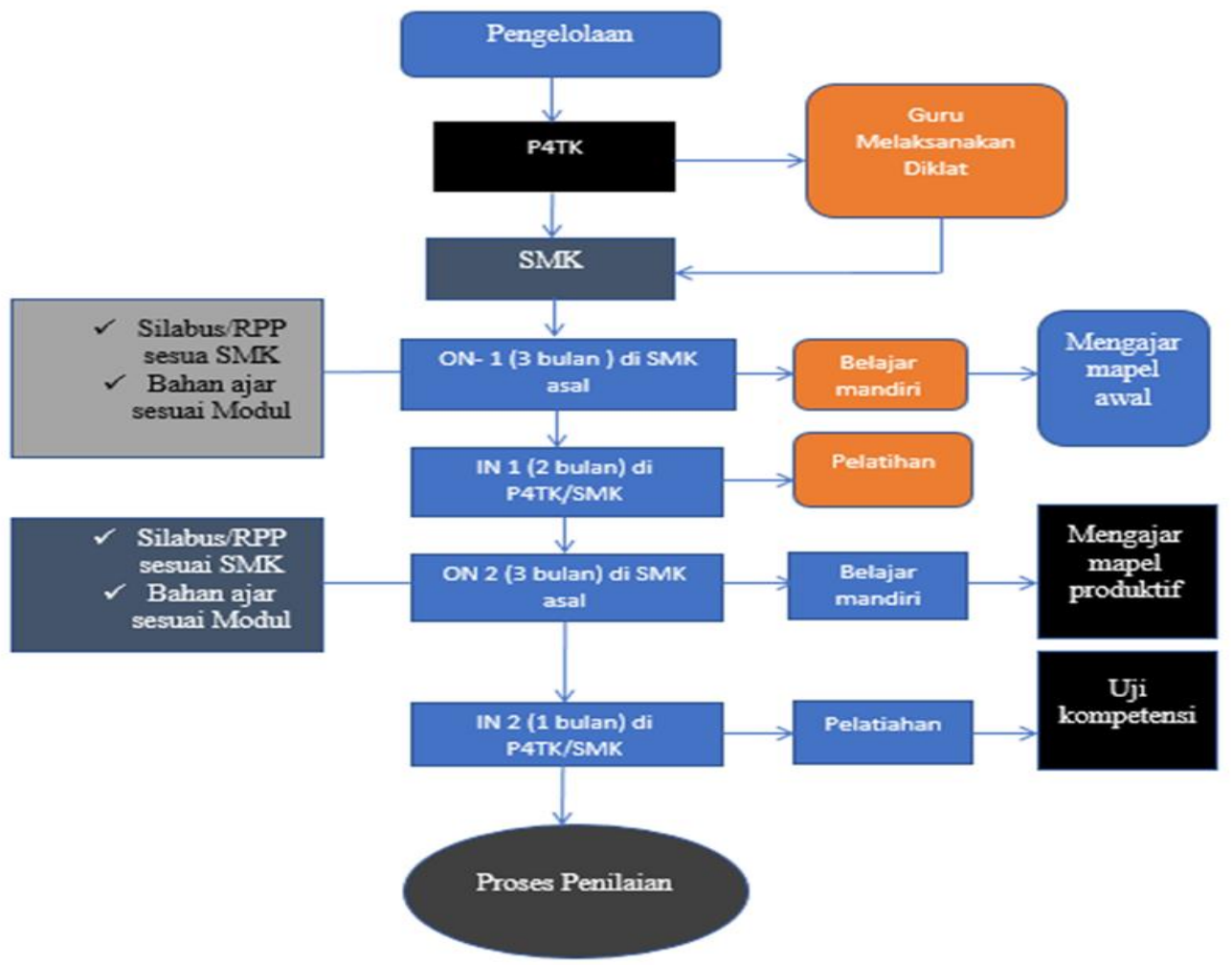

Gambar 2. Alur Pengelolaan Kegiatan Keahlian Ganda SMKN 12 Malang

Struktur progam yang digunakan dalam keahlian ganda semua sudah disusun oleh pusat/pppptk, sekolah tinggal melaksanakannya. Ada beberapa tahapan dari proses belajar terbimbing sampai proses pelatihan serta proses uji kompetensi. Dalam proses pembelajarannya (IN) menggunakan sebuah modul yang dijadikan acuan. Materi pada modul tersebut berisi mengenai pengetahuan pendagogik dan professional yang diterapkan ke peserta keahlian ganda. Hal tersebut dikarenakan agar siswa-siswi tetap mendapatkan materi yang sudah disusun oleh pihak SMKN 12 Malang. Modul yang digunakan peserta kealian ganda itu hanya sebagai wawasan materi saaat proses pelatihan (IN).

Proses belajar mengajar (ON) oleh peserta keahlia ganda menyesuaikan silabus sekolah, sama halnya dengan satuan acara pembelajaran/RPP. Dalam pembuatan RPP pun tidak sembarangan, RPP harus disesuaikan dengan KI/KD pada silabus agar berjalan sesuai dengan materi yang didapat siswa sebelunya. Pelatihan keahlian ganda menggunakan sebuah modul yang dijadikan acuan mengajar. Peserta keahlian ganda belajar menggunakan bahan ajar berupa modul tersebut.

Dalam proses belajar mengajar diperlukannya cara agar peserta dapat tertarik dalam pembelajaran. Salah satu cara tersebut yaitu pemanfaatan media pembelajaran yang memadai seperti halnya di SMKN 12 Malang persiapan mengenai media pembelajaran untuk pelaksanaan keahlian ganda sudah disiapkan dengan matang.

Proses pengelolaan progam keahlian ganda di SMKN 12 malang pun cukup jelas. Dari Dirjen GTK melalui PPPTK membuka pendaftaran peserta keahlian ganda secara online. Dari pihak SMKN 12 Malang membebaskan para guru menjadi peserta keahlian ganda yang sekiranya memenuhi syarat. Setelah nama-nama calon peserta keahlian ganda sudah tertera 
kemudian pihak sekolah mengirimkan nama-nama tersebut ke pusat. Apabila lolos seleksi peserta langsung melakukan diklat dan menjalani tahap ON 1-IN 1-ON 2-IN 2.

\section{Penilaian pengelolaan keahlian ganda di SMKN 12 Malang}

Penilain-penilain meliputi ON1-IN1-ON2-IN2. Mengenai penilaian keahlian ganda sebenarnya hampir sama hanya beda materinya saja. Dari peserta keahlian ganda mulai menuju ke ON 1, dimana dalam tahap tersebut peserta belajar mandiri 3 modul dan tetap mengajar mapel awal di sekolah asal.

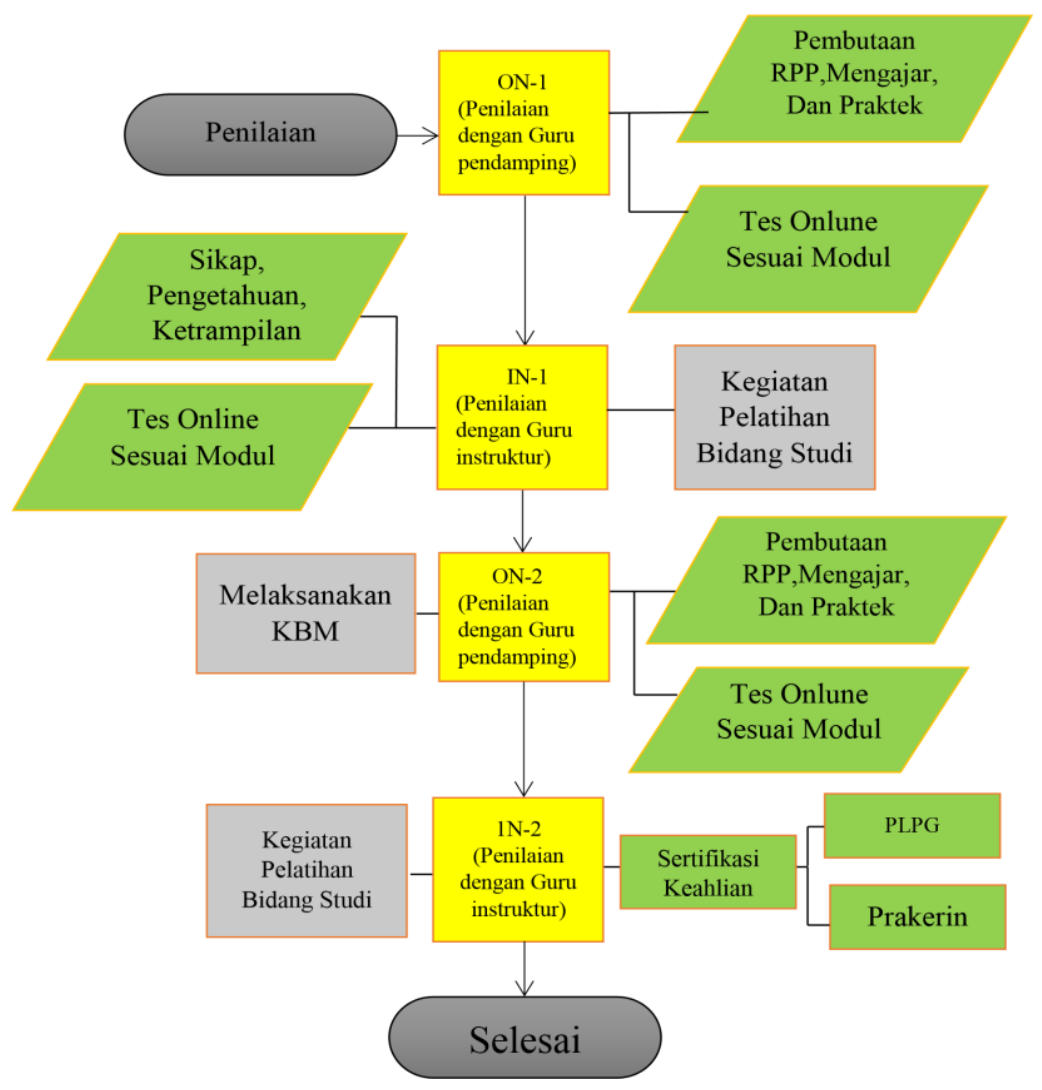

Gambar 3. Bagan Penilaian Pengelolaan Keahlian Ganda SMKN 12 Malang

Dalam tahap ON 1 peserta diberikan soal secara online sesuai isi materi dari 3 modul tersebut dan harus diselesaikan dengan waktu yang sudah ditentukan. Apabila Kriteria Capaian Minimal (KCM) memenuhi peserta keahlian ganda bisa melanjut ke tahap IN 1 dimana para peserta mengikuti pelatihan selama 2 bulan dengan materi 4 modul ditambah mengulas 3 modul waktu ON1. Pada tahan IN pun juga ada tes online apabila Kriteria Capaian Minimal (KCM) memenuhi bisa lanjut ke tahap ON 2, jika tidak memenuhi terdapat remedikal 1 kali. Penilaian ON 2 sama persis dengan penilaian ON 1 hanya beda materi yang disampiakan apabila Kriteria Capaian Minimal (KCM) di tahap 0N $2 \geq 55$ maka bisa lanjut ke tahap IN 2. Tahap penilaian IN 2 juga sama dengan IN1 apabila tes online lulus dengan nilai yang ditetapkan lanjut untuk tes sertifikasi keahlian. Ketika pada tahap terakhir (IN2) hasil akhir tes online selama ON1, IN1 dan ON2 penilaian akan muncul.

\section{PEMBAHASAN}

\section{Persiapan keahlian ganda di SMKN 12 Malang}

Menurut Widayana, Gede dan Mukhadis (2017) "The program is one of the main programs of the Ministry of Education and Culture (Kemendikbud) in empowering the development and empowerment of teachers and educators in Indonesia". Progam keahlian ganda bagi guru dapat membantu mengatasi solusi kekurangan guru produktif dan dapat meningkatkan profesionalisme guru sebagai tenaga pendidik serta mendapatkanya sertifikat pendidik dan sertifikat keahlian.

Dipilihnya guru instruktur dan pendamping yang berkompeten dan profesional pada bidangnya dimaksudkan agar setelah melakukan pelatihan peserta keahlian ganda dapat menjadi guru yang berkompeten di bidang produktif. Senada dengan 
Fatma (2018) dalam jurnalnya guru yang profesional adalah orang yang terdidik dan terlatih dengan baik, serta memiliki pengalaman yang kaya di bidangnya. Dalam konteks tersebut guru profesional yang dimaksud ialah guru intruktur dan guru pendamping keahliah ganda.

Pelatihan peserta keahlian ganda pastinya akan bentrok apabila jadwal tidak diatur sebelumnya karena pelatihan juga membutuhkan ruang kelas dan ruang bengkel, maka dari itu jadwal pengaturan peserta keahlian ganda dan siswa SMK harus diperhatikan. Penjadwalan merupakan suatu proses pengorganisasian waktu untuk mendapatkan waktu yang efektif dan optimal. Tidak hanya jadwalnya saja, peralatannya pun juga harus disiapkan. Apabila peralatan untuk praktek memadai juga akan mempengaruhi lancarnya prestasi belajar pada saat pelatihan.

\section{Pengelolaan kegiatan keahlian ganda di SMKN 12 Malang}

Ada beberapa tahapan dari proses belajar terbimbing sampai proses pelatihan serta proses uji kompetensi. Dalam proses pembelajarannya (IN) menggunakan sebuah modul yang dijadikan acuan. Materi pada modul tersebut berisi mengenai pengetahuan pendagogik dan professional yang diterapkan ke peserta keahlian ganda. Menurut Sahidu, dkk (2018 ) dalam jurnalnya mengatakan bahwa secara rinci kompetensi pedagogik meliputi.

(1) memahami karakteristik peserta didik dari aspek fisik, sosial, moral, kultural, emosional dan intelektual; (2) memahami latar belakang keluarga dan masyarakat peserta didik dan kebutuhan belajar dalam konteks kebhinekaan budaya; (3) memahami gaya belajar dan kesulitan belajar peserta didik; (4) memfasilitasi pengembangan potensi peserta didik; (5) menguasai teori dan pinsip belajar serta pembelajaran yang mendidik; (6) mengembangkan kurikulum yang mendorong keterlibatan peserta didik dalam pembelajaran; (7) merancang pembelajaran yang mendidik; (8) melaksanakan pembelajaran yang mendidik; dan (9) mengevaluasi proses dan hasil belajar.

Dalam jurnalnya Widayati (2008) menjelaskan bahwa kompetensi profesional adalah kompetensi profesional berkaitan dengan kemampuan guru untuk menguasai pengetahuan dari bidang studi yang diajarkan secara luas dan mendalam, serta kemampuan guru untuk meningkatkan kualitas pembelajaran yang dilaksanakannya. Pengetahuan pendagogik dan professional itulah yang dijadikan bekal untuk mengajar siswa-siswi SMKN 12 Malang.

Guna menunjangnya proses pembelajaran dibutuhkannya sebuah bahan ajar yang dirancang semenarik mungkin. Menurut Mursyidi (2015) bahan ajar yang kurang menarik dan kurangnya minat peserta didik dalam mempelajari bahan ajar akan membuat peserta didik kurang memahami apa yang dipelajarinya dan tidak bisa mengikuti pembelajaran dengan baik.

Selain bahan ajar media pembelajaran juga dapat menarik minat peserta dalam proses pembelajaran. Menurut Ali (2009) keberhasilan pembelajaran sangat ditentukan oleh dua komponen utama yaitu metode mengajar dan media pembelajaran.

\section{Penilaian pengelolaan keahlian ganda di SMKN 12 Malang}

Penilaian dibutuhkan guna mengetahui sejauh mana peserta tersebut dalam menguasai materi yang diberikan. Penilain-penilain tersebut meliputi ON1-IN1-ON2-IN2. Mengenai penilaian keahlian ganda sebernya hampir sama hanya beda materinya saja. Dari peserta keahlian ganda mulai menuju ke ON 1, dimana dalam tahap tersebut peserta belajar mandiri 3 modul dan tetap mengajar mapel awal di sekolah asal. Dalam tahap ON 1 peserta diberikan soal secara online sesuai isi materi dari 3 modul tersebut dan harus diselesaikan dengan waktu yang sudah ditentukan. Apabila Kriteria Capaian Minimal (KCM) memenuhi peserta keahlian ganda bisa melanjut ke tahap IN 1 dimana para peserta mengikuti pelatihan selama 2 bulan dengan materi 4 modul ditambah mengulas 3 modul waktu ON1. Penilaian ON2 dan IN2 sama dengan penilaian ON1 dan IN1.

\section{PENUTUP}

\section{Kesimpulan}

Salah satu cara untuk memperoleh hasil yang memuaskan dalam melakukan pelatihan harus mempersiapkannya dengan matang. Langkah awal yang dilakukan untuk menjadi calon peserta progam keahlian ganda harus memperhatikan syarat/kriteria yang telah ditentukan oleh Dirjen GTK.

Kepala Sekolah SMKN 12 Malang juga menunjuk guru yang berkompeten dibidangnya untuk dijadikan guru instruktur, yang akan diberi pelatihan oleh pihak PPPPTK dan juga pemilihan guru pendamping.

Pihak SMKN 12 Malang pun juga sudah mengatur jadwal kegiatan peserta keahlian ganda yang disesuaikan dengan guru yang ikut progam keahlian ganda. Mengenai persiapan peralatan praktek dan teori di SMKN 12 Malang sudah dipastikan cukup memadai dan siap digunakan dalam kegiatan praktek tersebut. 
Secara garis besar struktur progam keahlian ganda di SMKN 12 Malang ini mengacu pada pusat. Sekolah hanya menyesuaikan dan menerapkan proses keahlian ganda yang telah ditetapkan dari pusat. Sama halnya Silabus dan RPP, apabila peserta mengajar yaitu pada waktu ON maka silabus dan RPP yang digunakan tetap sesuia dengan sekolah tempatnya mengajar. Proses pengelolaan keahlian ganda di SMKN 12 Malang bisa dibilang tidak rumit yaitu pusat membuka pendaftaran online melalui website, apabila ada guru dari SMKN 12 Malang ingin mendaftarkan diri dari pihak sekolah membebaskan siapa saja yang ingin daftar menjadi peserta keahlian ganda yang sekiranya memenuhi syarat.

Penilain ON1-IN1-ON2-IN2 prinsipnya sama hanya beda materinya saja yang digunakan ketika ujian online. Terdapat beberapa faktor pendukung pelaksanaan keahlian ganda di SMKN 12 Malang. Pertama perlunya persetujuan dari kepala sekolah, apabila Kepala Sekolah menghambatnya pasti pelaksanaan keahlian ganda tidak berjalan lancar. Kedua, fasilitas yang memadai, dalam hal ini fasilitas yang dimaksud ialah berupa sarpras dan guru pendamping yang kompeten. Faktor pendukung yang terakhir itu berasal dari diri kita sendiri yaitu minat belajar.

Saran

Berdasarkan simpulan di atas, berikut saran yang dapat penulis sampaikan. Kepada guru SMKN 12 Malang Diharapkan dengan adanya pengelolaan keahlian ganda di SMKN 12 Malang guru yang mengikuti progam tersebut menjadikannya wawasan dan ilmu baru, jangan menjadikannya beban tugas dan Mengajar menjadi lebih bersemangat karena adanya tantangan untuk selalu belajar teknologi dan ilmu baru.

Kepada SMKN 12 Malang diharapkan untuk menambahkan alat yang digunakan untuk praktek peserta keahlian ganda agar tidak bergantian dengan siswa.

Kepada Kementrian Pendidikan dan Kebudayaan agar proses pelatihan pada tahap IN memberikan hasil yang maksimal, disarankan jangka waktu yang sedikit lebih panjang dari sebelumnya agar benar-benar menguasai materi terutama guru yang sebelumnya mengampu mata pelajaran adaptif maupun normatif.

Kepada Jurusan Teknik Mesin FT UM mencarikan terobosan kerjasama agar lulusannya dengan cepat mendapatkan pekerjaan sesuai prodi masing-masing terutama untuk S1 PTM. Perlu kerjasama dengan SMK dan Dinas Pendidikan dalam penyerapan tenaga guru.

Kepada peneliti selanjutnya disarankan kepada peneliti selanjutnya untuk mengaji lebih dalam mengenai pelaksanaan progam keahlian ganda, karena masih minimnya referensi dari penelitian ini. Agar informasi yang didapat lebih lengkap dan konkrit.

\section{DAFTAR RUJUKAN}

Ali, M. 2009. Pengembangan Media Pembelajaran Interaktif Mata Kuliah Medan Elektromagnetik. Jurnal Edukasi,5(1) , 1118. Dari

https://scholar.google.co.id/citations?user=WujtCR8AAAAJ\&hl=id

Arikunto, S. 2013. Prosedur Penelitian Suatu Pendekatan Praktik. Jakarta: PT Rineka Cipta.

Benhabib, J., \& Spiegel, M. M. 1994. The Role Of Human Capital In Economic Development Evidence from Aggregate CrossCountry Data. Journal of Monetary Economics, 34(2), 143-173. Dari https://sciencedirect.com.

Dewi, P.F. 2018. Pengaruh Guru Profesional Dan Iklim Sekolah Terhadap Mutu

Pembelajaran SD Muhammadiyah Terpadu Ponorogo.

(online),http://jurnal.stainponorogo.ac.id/index.php/muslimheritage/article /view/1116/783.

Direktorat Jenderal Guru dan Tenaga Kependidikan. 2016. Pedoman Program Sertifikasi Keahlian dan Sertifikasi Pendidik Bagi Guru SMK/SMA (Keahlian Ganda). Jakarta: Kementrian Pendidikan dan Kebudayaan.

Moleong, L. J. 2005. Motodologi Penelitian Kualitatif. Bandung: PT Remaja Rosdaka.

Mursyidi, S. Qomar. 2015. Pengembangan Bahan Ajar IPS Kelas VII Pada SubSubtema Pemanfaatan Sumber Daya Alam. Skripsi thesis, Universitas Muhammadiyah Surakarta.

Putra, N. 2013. Penelitian Kualitatif IPS. Bandung: PT Remaja Rosdaka.

Rudin, D. A. 2017. Studi Kelengkapan dan Kelaikan Alat Pelindung Diri (APD) dan Peralatan Las Pada Laboratorium Pengelasan SMAW, TIG dan MIG Jurusan Teknik Mesin Universitas Negeri Malang. Skripsi tidak diterbitkan. Malang: Fakultas Teknik Universitas Negeri Malang.

Sahidu. H,. dkk. 2018. Penyuluhan Tentang Lesson Study (LS) Untuk Meningkatkan Kompetensi Pendagogik Guru-Guru Di MAN 2 Mataram. Jurnal Pendidikan Dan Pengabdian masyarakat, Vol. 1 No. 1, Februari 2018.

Tirtarahardja, U \& Sula, L. 2005. Pengantar Pendidikan. Jakarta: PT Asdi Mahasatya.

Widayana \& Mukhadis, A. 2017. Development of Vocational Education as Demands Revitalization of Vocational High School in Dual Skills Program. Vol. 04 No. 12; 2017 by authors and International Journal of Research and Engineering.

Widayati, Ani. 2008. Penelitian Tindakan Kelas. Jurnal Pendidikan Akuntansi Indonesia, Vol. VI No. 1 Hal. 87 - 93. 